\title{
Differentiation of visual spectra and nuptial colorations of two Paratanakia himantegus subspecies (Cyprinoidea: Acheilognathidae) in response to the distinct photic conditions of their habitats
}

\author{
Chia-Hao Chang ${ }^{1,2}$, Yi Ta Shao ${ }^{3,4}$, Wen-Chung Fu' ${ }^{3}$ Kazuhiko Anraku ${ }^{5}$, Yeong-Shin Lin ${ }^{1,6}$ and Hong Young Yan ${ }^{3,7^{*}}$
}

\begin{abstract}
Background: Vision, an important sensory modality of many animals, exhibits plasticity in that it adapts to environmental conditions to maintain its sensory efficiency. Nuptial coloration is used to attract mates and hence should be tightly coupled to vision. In Taiwan, two closely related bitterlings (Paratanakia himantegus himantegus and Paratanakia himantegus chii) with different male nuptial colorations reside in different habitats. We compared the visual spectral sensitivities of these subspecies with the ambient light spectra of their habitats to determine whether their visual abilities correspond with photic parameters and correlate with nuptial colorations.

Results: The electroretinogram (ERG) results revealed that the relative spectral sensitivity of $P$. $h$. himantegus was higher at $670 \mathrm{~nm}$, but lower at $370 \mathrm{~nm}$, than the sensitivity of $P$. h. chii. Both bitterlings could perceive and reflect UV light, but the UV reflection patterns differed between genders. Furthermore, the relative irradiance intensity of the light spectra in the habitat of P. h. himantegus was higher at long wavelengths (480-700 nm), but lower at short wavelengths (350-450 nm), than the light spectra in the habitats of $P$. h. chii.

Conclusions: Two phylogenetically closely related bitterlings, $P$. h. himantegus and $P$. h. chii, dwell in different waters and exhibit different nuptial colorations and spectral sensitivities, which may be the results of speciation by sensory drive. Sensory ability and signal diversity accommodating photic environment may promote diversity of bitterling fishes. UV light was demonstrated to be a possible component of bitterling visual communication. The UV cue may assist bitterlings in gender identification.
\end{abstract}

Keywords: Bitterling; Electroretinogram; Sensory drive; UV reflection pattern

\section{Background}

Vision is an important sensory modality in fish, with the exception of some fishes, such as cave-dwelling species without eyes. Almost all fishes, from those inhabiting shallow and clear waters to those in the aphotic zone in the deep ocean, can perceive visual signals (Pitcher 1986) in order to communicate, find mates, forage for food,

\footnotetext{
* Correspondence: hyyan@gate.sinica.edu.tw

${ }^{3}$ Sensory Physiology Laboratory, Marine Research Station, Academia Sinica,

I-Lan, Taiwan

7Hanse-Wissenschaftskolleg Institute of Advanced Study, Delmenhorst,

Germany

Full list of author information is available at the end of the article
}

avoid predators, camouflage, or navigate (Hawryshyn 1992; Losey et al. 1999).

Light spectra in aquatic environments are distinct from those on land. Not just water itself, but also suspended materials (e.g., mineral particles, detritus, and planktons), can selectively absorb or scatter different wavelengths of light (Litjens et al. 1999). Since the underwater photic environments may be affected by depth and suspended materials as well as unique features of the habitats, fish under different photic conditions should physiologically adjust its spectral sensitivity in order to enhance detection ability by maximizing the visual contrast (Endler 1992; Lythgoe 
1984). For example, the spectral sensitivity of milkfish (Chanos chanos), humpback salmon (Oncorhynchus gorbuscha), and yellowfin tuna (Thunnus albacares) ontogenetically change to fit the photic environment during each developmental stage (Chang et al. 2009a; Cheng and Flamarique 2004; Loew et al. 2002). Moreover, it has been reported that spectral sensitivity has evolved to adapt to environmental light parameters in cichlids, seabreams, and moray eels (Seehausen et al. 2008; Wang et al. 2011; Wang et al. 2009), especially, the adaptations of RH1 and LWS opsins to light environments which are documented in cichlid fishes (Sugawara et al. 2005; Terai et al. 2006), as well as in different populations of three-spined stickleback (Gasterosteus aculeatus) and guppy (Poecilia reticulata) (McDonald and Hawryshyn 1995; Tezuka et al. 2014). The retinal photoreceptor cells of fishes utilize visual pigments, which contain a chromophore (11-cis-retinal, A1 retinal, or 11-cis-3,4-dehydroretinal, A2 retinal) and opsin, to capture photons. Variations in spectral sensitivity mainly result from the alternative usage of different opsin genes (Flamarique 2013; Johnson et al. 2013; Kasagi et al. 2015; Kondrashev et al. 2013; Valen et al. 2013). Furthermore, sexual selection favors individuals that can display visual signals that are readily distinguishable from the background (Hurtado-Gonzales et al. 2014; Miyagi et al. 2012; Morrongiello et al. 2010; Selz et al. 2014). Therefore, in addition to their link with visual properties, photic environments may also influence overall body coloration of fish.

A good example of the interactions among the photic environment, spectral sensitivity, and nuptial coloration is observed in two cichlids inhabiting Lake Victoria, Pundamilia nyererei and Pundamilia pundamilia. These two cichlids are closely related and $P$. nyererei is sympatric with $P$. pundamilia over its distribution range; moreover, they are morphologically and anatomically similar. Females of these two species are hard to tell from each other, but males of them are obviously different with distinct coloration: male $P$. pundamilia is metallic blue-grey and male $P$. nyererei is bright red dorsally and yellow laterally (Maan et al. 2004). Also, P. nyererei lives in deeper water than P. pundamilia (Seehausen and Bouton 1997), and so the former is relatively exposed to more red light with a proportionally greater wavelength (Maan et al. 2006). In response to variations in ambient light environments, these two species have evolved distinct spectral sensitivities and nuptial colorations (Maan et al. 2006; Miyagi and Terai 2013).

Bitterling (Acheilognathidae, Cyprinoidea) are cyprinids, distributed over East and Southeast Asia and Europe. They inhabit various lowland freshwater habitats, such as lakes, rivers, and ditches (Kottelat and Freyhof 2007), and have evolved a symbiotic relationship with freshwater mussels (family Unionidae) for reproduction. The reproductive success of male bitterlings (which establish a territory and guard mussels from rivals) is mainly dependent on body size (Casalini et al. 2009; Reichard et al. 2008). However, a recent study demonstrated that nuptial coloration is a critical factor for female mate choice and malemale competition (Smith et al. 2014).

In Taiwan, two native Paratanakia bitterlings, Paratanakia himantegus himantegus and Paratanakia himantegus chii (Fig. 1), are phylogenetically related (Chang et al. 2014; Chang et al. 2009b), and their distributions largely overlap on a geographical scale; however, they are rarely sympatric. Usually, the two bitterlings are found in separate microhabitats: $P$. h. chii mainly dwells in shallow floodplain habitats, such as irrigation channels of rice paddy fields, whereas $P$. h. himantegus is commonly found in lakes and ponds (Chen and Chang 2005; Chen et al. 2012). The most obvious morphological difference between the two bitterlings is the nuptial coloration (mating signals). Breeding males of $P$. h. himantegus possess a red stripe on their dorsal fin, red patches on the operculum and pectoral fin, and red irises, whereas $P$. h. chii breeding males have a yellow-white stripe on the dorsal fin, and their irises are not red (Chen and Chang 2005).

The perception of visual signals is determined by two components: the physical characteristics of a habitat and the sensory properties of a receiver (Endler 1990); therefore, a change in one of these two components tends to drive the development of substitute signals in response to variable habitats (Chunco et al. 2007; Endler 1980), which has been demonstrated by several studies (Dalton et al. 2010; Fuller et al. 2005; Gray et al. 2008; Hoffmann et al. 2007). Based on the observation that the two aforementioned and closely related bitterlings exhibit distinct nuptial colorations, it is hypothesized that the differences in their nuptial colorations may be related to variations in photic properties of its habitats and/or spectral sensitivities of the fish. To test this hypothesis, the spectral sensitivities of these two bitterlings were recorded with electrophysiological method and the light spectra of their habitats were measured and compared.

\section{Methods}

\section{Subjects}

Fish were caught from Chinlung Lake, Hsichih, New Taipei City $(P . h$. himantegus) and Dashi, Taoyuan County $(P . h$. chii). These two sites belong to the Tamsui River basin. All fish were collected during the spawning season (July 2013). The males exhibited nuptial coloration and the females had long ovipositors. Fish were 25 to $40 \mathrm{~mm}$ in standard length. Fish were kept in the laboratory in two 36-L aquaria (separated by taxa) under a natural photoperiod, with water temperature maintained at $25 \sim 28{ }^{\circ} \mathrm{C}$. They were fed ad libitum with artificial fish feed or frozen Artemia twice a day. Specimen collection and experiments 

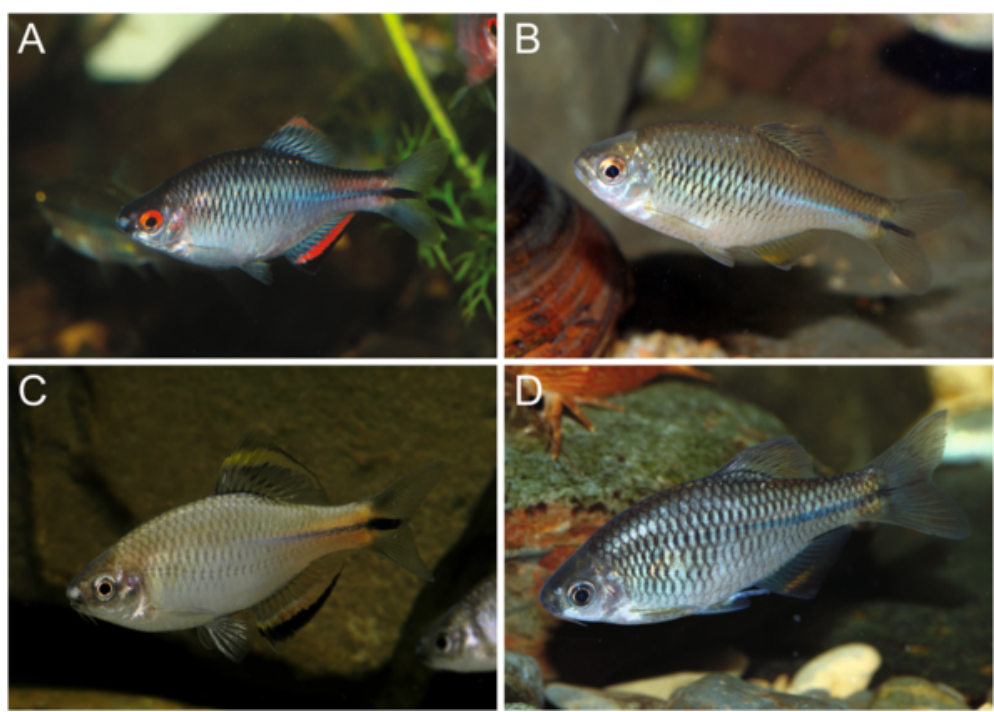

Fig. 1 Photos of studied species taken in an indoor aquarium. a Male P. himantegus himantegus; b female P. h. himantegus; c male Paratanakia himantegus chii; d female P. h. chii. [Photos were taken by Dr. Yun-Ching Chang and Mr. Ta-Ching Chang]

were performed with permission (RFiZOOHY20060701) from the Institutional Animal Care and Use Committee (IACUC) of Academia Sinica.

\section{Electroretinogram recording}

Electroretinogram (ERG) recordings were mainly modified from Shao et al. (2014). Fish were anesthetized with 0.025 $\%$ buffered MS-222 (ethyl 3-aminobenzoate, methanesulfonic acid salt), and then immobilized through an injection of gallamine triethiodide (Flaxedil; Sigma, St. Louis, MO, USA.), a neuromuscular junction blocking agent, into the dorsal muscle (0.4-0.6 $\mu$ g per gram of body weight). Each fish was wrapped in wet KimWipes (Kimberley-Clark Taiwan, Taipei) to prevent skin from scraping or drying, and a small tube was inserted into the mouth to deliver well-oxygenated water to the gills. Immobilized fish were kept under dark conditions for at least $1.5 \mathrm{~h}$ for dark adaptation before the ERG recording. ERG tests were performed as described previously (Morita et al. 1997; Seeliger et al. 2002; Shao et al. 2014). A 100-W halogen lamp (Osram $64637100 \mathrm{~W} / 12 \mathrm{~V}$ ) in a lamp housing device (Nikon C-FI 115, Japan) was used as the light source for tests of visible spectra $(400-670 \mathrm{~nm})$. For the shorter wavelengths $(\leq 370 \mathrm{~nm})$, a custom-made UV curing device (Great Lighting Corp. $100 \mathrm{~W} / 365 \mathrm{~nm}$ ) was used as the light source. A series of neutral density (ND) filters (Andover, NH, USA) were used to reduce the light intensity in $0.3 \log$ unit steps, from -0.3 to $-4.8 \log$ units. Peak photon fluxes at each wavelength were determined using a USB 2000 spectrophotometer (Ocean Optics, USA), calibrated by LC-1-cal (Ocean Optics, USA) with OODBase32 software (Ocean Optics, USA), at the fish eye surface. A shutter (Sutter Instrument Lambda SC, USA) was used to provide fixed durations of light stimuli: 10 stimuli, each of $20 \mathrm{~ms}$ in duration, with an inter-stimuli interval of $5 \mathrm{~s}$. The ERG tests started from the lowest light intensity, and ND filters were adjusted step-by-step to increase stimuli intensity (16 steps to reach the maximum). ERG signals were recorded using Teflon-coated insulated silver electrodes ( $63.5 \mu \mathrm{m}$ in diameter), and the Telfon on the tip end $(5 \mathrm{~mm})$ was removed and chlorinated to enhance picking up of evoked potentials. The recording electrode was positioned on the cornea, and the reference electrode was placed on the head. The signals from both electrodes were amplified $20 \mathrm{k}$-fold and filtered with a high-low band pass filter set between 1 and $3000 \mathrm{~Hz}$ (ER-1, Cygnus Technology Inc. USA). The signals were digitized at a $2-\mathrm{kHz}$ sampling rate with PowerLab 4/25 (ADInstruments, Inc. ML845, Australia) and recorded with Scope 3 data acquisition software (ADInstruments, Inc. Australia). The recorded signals were analyzed using custom-made software (programmed by K. Anraku). Signals recorded at each step (100 to $700 \mathrm{~ms}$ after stimuli) were compared to the model ERG trace obtained at maximum light stimuli using the correlation method. The replicates of waveforms from each test were compared using Spearman's correlation test. Our pilot study revealed that when a correlation coefficient $(r)$ between two replicates was less than 0.7, the two ERG traces showed little resemblance. Hence, ERG traces were considered valid when $r$ was greater than 0.7 and the $b$-wave latency time delay was less than $100 \mathrm{~ms}$ (Seeliger et al. 2002). Deflection of the ERG trace was taken as an indication of the light intensity threshold of the particular wavelength (Morita et al. 1997). Sensitivity was defined as - $\log 10$ of the threshold for each tested wavelength. To remove 
variations between trials, values for each individual were standardized to a $0-100 \%$ scale, where $100 \%$ indicated the maximum sensitivity spectrum (Lisney et al. 2010). After standardization, the sensitivity values of the two bitterlings for each light wavelength stimulus were compared using Tukey's pairwise comparisons (one-way ANOVA). In this study, eight $P$. $h$. himantegus individuals (four males and four females) and nine $P$. h. chii individuals (six males and three females) were used for recordings.

\section{Body UV reflection pattern}

Fish were anesthetized with buffered MS-222 before being photographed. The body UV reflection pattern was recorded using a Nikon D70 camera equipped with a Nikon 105-mm micro lens. The whole process was completed inside a dark room, where fish bodies were illuminated using two UV lamps (UVGL-58 P/N 95-0007-05, long wave mode, $367 \mathrm{~nm})$. A UV passing filter (B + W 403 $52 \mathrm{~mm}$ ) and an IR cut filter (B + W $48952 \mathrm{~mm}$ ) were mounted on the lens to block any possible ambient light leakage. The spectral transmission ranges of these two filters are available online (http://diglloyd.com/articles/ Filters/spectral-B+W-403.html). The UV reflection patterns of one male and one female of each subspecies were photographed.

\section{Ambient light spectra}

The ambient light spectra of four habitats, including the only two known habitats of P. h. chii in Taiwan (Dashi Town, Taoyuan County and Longtan Township, Taoyuan County), and two typical habitats of $P$. h. himantegus (Chinlung Lake, Hsichih, New Taipei City and Jiaoxi Township, Yilan County), were measured using a USB2000 spectrometer with a waterproof fiber optic cable (QP1000-2-UV-VIS) (Ocean Optics, Dunedin, FL, USA), $1000 \mu \mathrm{m}$ in diameter and $2 \mathrm{~m}$ in length; absolute spectral irradiance was measured at three to five sites in each sampling location. Before each measurement, USB-2000 was calibrated with calibration light sources, LS-1-cal (Ocean Optics, Dunedin, FL, USA), with OODBase32 software (Ocean Optics, Dunedin, FL, USA). The light in air was measured upward above the water surface, and the light underwater was measured both upward and sideway at a depth of $25 \mathrm{~cm}$ from the water surface at all locations. The underwater sideway light spectrum was the arithmetic mean of two scans in the sun and anti-sun directions (Flamarique et al. 2013). Habitat photic parameters were measured between 10:00 and 14:00 in October, 2014. The 25-cm depth is the averaged depths of the trenches or the near-shore area of the pond, where bitterling breeding pairs and hosting mussels were found. The relative spectral irradiance was smoothed by a factor of 15 using a simple moving average (McLean et al. 2007), and then normalized to a $0-100 \%$ scale, where $100 \%$ indicated the maximum intensity spectrum. Light spectra of the typical habitats of $P$. h. chii and $P$. h. himantegus were the geometric means of the relative spectral irradiance measured in the respective locations. Moreover, the light spectra curves of the typical habitats were compared by Spearman's correlation coefficients with two-tailed tests, which were performed with SPSS v.14 (SPSS Inc., Chicago, IL, USA).

\section{Results}

The relative visual spectra of these two Paratanakia subspecies measured with ERG recording is shown in Fig. 2, which showed that bitterlings of both subspecies are able to detect light within a range of $370 \mathrm{~nm}$ to 670 $\mathrm{nm}$ under dark adaptation conditions. The highest sensitivity (lowest threshold) was found at the wavelength of $440 \mathrm{~nm}$ for $P$. h. himantegus and $460 \mathrm{~nm}$ for $P$. h. chii. Both fishes were less sensitive (higher threshold) to light at a wavelength of $670 \mathrm{~nm}$ as compared with other tested wavelengths. No differences in thresholds of spectral sensitivity were observed between gender for either species. To obtain relative spectral sensitivity values, the sensitivity of $P$. h. himantegus was normalized to the stimulation intensity of the threshold at $440 \mathrm{~nm}$ (which was set as $100 \%$ ), and the sensitivity of $P$. h. chii was normalized to the stimulation intensity of the threshold at $460 \mathrm{~nm}$. The relative visual spectra of the two subspecies are of inverted U shapes, with some variations (Fig. 2). The relative spectral sensitivity curve of $P$. h. himantegus displayed a single peak at $440 \mathrm{~nm}$, but that of $P$. h. chii exhibited two peaks; a maximum sensitivity peak at $460 \mathrm{~nm}$ and a secondary peak at $400 \mathrm{~nm}$ (99.73\%). Compared to the most sensitive wavelength for the respective fish, the

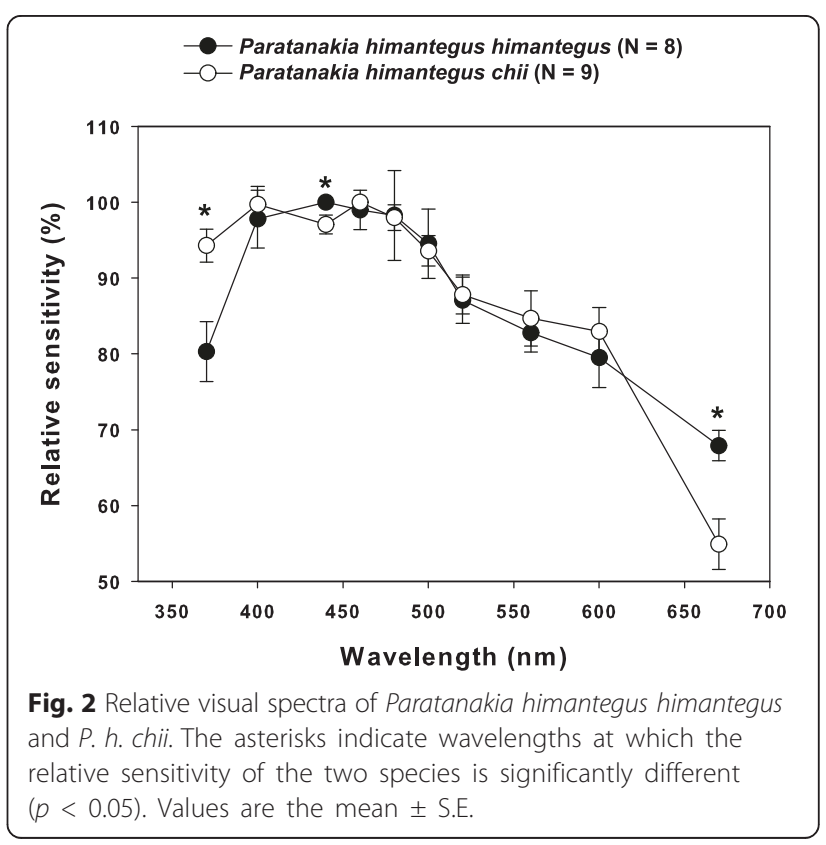


relative sensitivity of the least sensitive wavelengths (670 nm) was only $70 \%$ in $P$. h. himantegus and $55 \%$ in $P$. $h$. chii. Examining the two ends of the visual spectra revealed that the relative sensitivity at $670 \mathrm{~nm}$ is roughly the same as that at $370 \mathrm{~nm}$ for $P$. h. himantegus, but in $P$. h. chii, the relative sensitivity at $670 \mathrm{~nm}$ is much lower than that at $370 \mathrm{~nm}$ (Fig. 2). Tukey's pairwise (one-way ANOVA) tests were performed to demonstrate that $P$. $h$. himantegus was more sensitive at 670 and $440 \mathrm{~nm}$ but less sensitive at $370 \mathrm{~nm}(p<0.05)$ than P. h. chii (Fig. 2).

Examination of body UV reflection patterns showed that both species reflect UV light (Fig. 3). The dorsal and anal fins of both $P . h$. himantegus and $P . h$. himantegus males under visible light were more vividly colored (Fig. 3(A-VIS
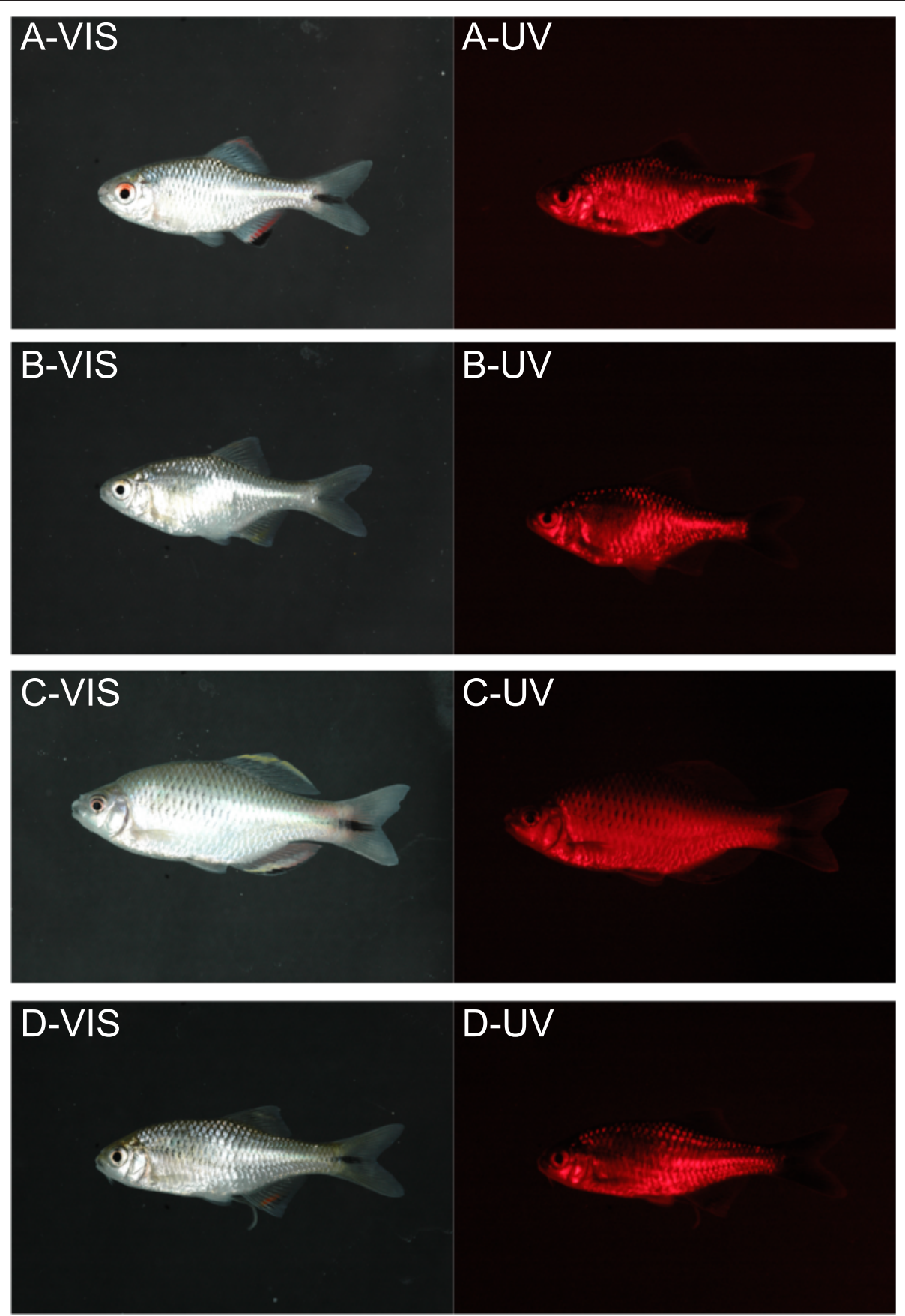

Fig. 3 Photos of body reflection patterns of Paratanakia himantegus himantegus and $P$. h. chii under UV light (UV) and visual light (VIS). (A-UV) Male P. himantegus himantegus; (A-VIS) male P. h. himantegus; (B-UV) female P. h. himantegus; (B-VIS) female P. h. himantegus; (C-UV) male P. h. chii; (C-VIS) male P. h. chii; (D-UV) female P. h. chii; (D-VIS) female P. h. chii 
and C-VIS)) than those of females (Fig. 3(B-VIS and $\mathrm{D}-\mathrm{VIS})$ ). Nevertheless, the fins of neither males nor females reflected UV (Fig. 3(A-UV, B-UV, C-UV and DUV)). There is no clear difference in UV reflection pattern between subspecies. Males of both fishes reflected UV throughout the body (Fig. 3(A-UV, and C-UV)), whereas females had a non-reflecting region above the pelvic fin. UV reflection by the ventral part was stronger than reflection by the dorsal part of the body (Fig. 3(B-UV and D-UV)).

The original data of relative ambient spectra gathered from four habitats were shown in Additional file 1. The light spectra in the air in the sampled habitats were largely consistent (Spearman's rho $r=0.781, p<0.001$ ) (Fig. 4a); however, significant differences of light transmission underwater were observed upon comparing spectral irradiance from various habitats. The irradiance of upward light in the habitat of $P$. h. himantegus was higher at relatively long wavelengths $(480-700 \mathrm{~nm})$, but lower at shorter wavelengths $(350-450 \mathrm{~nm})$, than in the habitats of $P$. h. chii (Fig. 4b). Furthermore, Spearman's correlation coefficients were used to show that the upward underwater spectral curve in the habitats of $P$. $h$. himantegus and $P$. h. chii were not correlative $(r=0.161$, $p<0.001)$. At $670 \mathrm{~nm}$, i.e., red light, the relative irradiance in the habitat of $P$. h. himantegus was more than double that in the habitat of $P$. h. chii. However, the relative irradiance in the UV light spectrum, i.e., $370 \mathrm{~nm}$, was far higher in the $P$. h. chii habitat than that in $P . h$. himantegus habitat (Fig. 4b). The sideways light spectra of the $P$. $h$. himantegus habitat were shifted toward longer wavelengths as compared to the spectra of the habitat of P. h. chii (Spearman's rho $r=0.559, p<0.001$ ) (Fig. 4c). The highest relative irradiance in the $P . h$. himantegus habitat was observed at $560 \mathrm{~nm}$, whereas the relative irradiance in the $P$. $h$. chii habitat peaked at a shorter wavelength, $455 \mathrm{~nm}$ (Fig. 4c).

\section{Discussion}

According to the surveys carried out by Taiwan Conservation Association of Native Fishes (TCANF), the two bitterlings examined here live in different habitats. $P . h$. chii prefers shallow habitats, such as irrigation channels of rice paddy fields, whereas $P$. h. himantegus prefers deeper water, including lakes and ponds (TCANF unpublished data). Therefore, although these two subspecies can coexist in one large drainage system, they are seldom sympatric in distribution. These two typical habitats, ditch and pond, not only differ in terms of depth and current but may also differ in their photic environments. Due to phytoplankton, the ambient light spectra of turbid or eutrophic waters may have higher relative irradiance at longer wavelengths (Bowling et al. 1986; Jerlov 1976). As compared with the habitats of $P$. h. himantegus, the habitats of $P . h$.

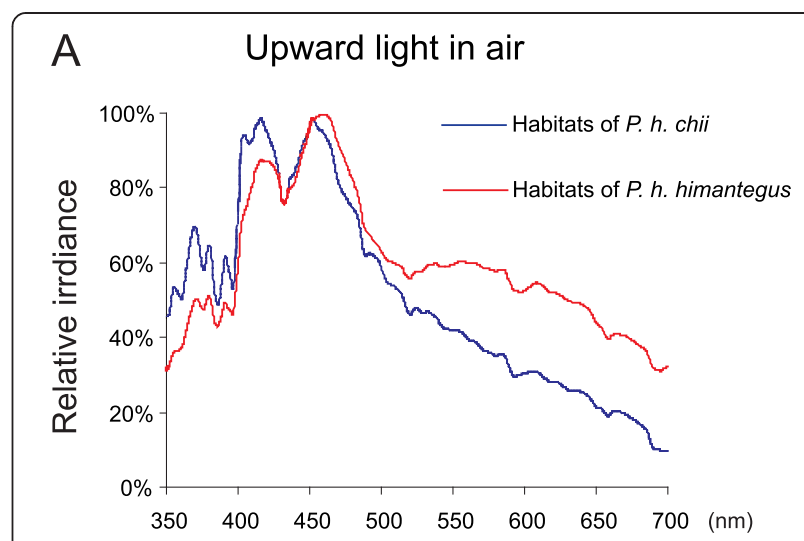

B Underwater upward light

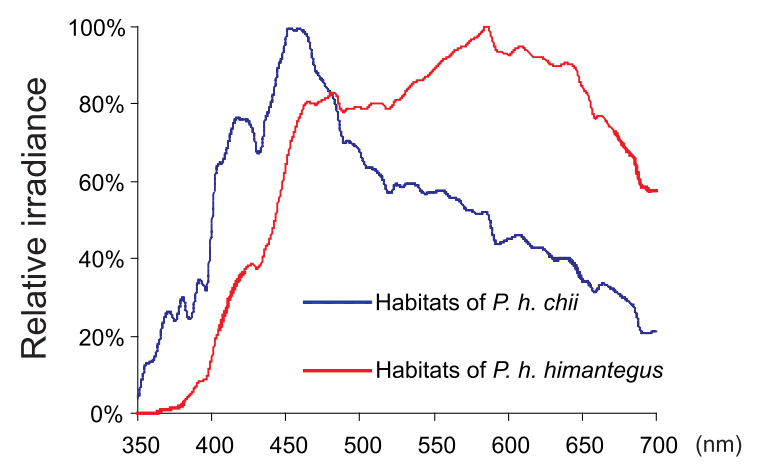

C Underwater sideward light

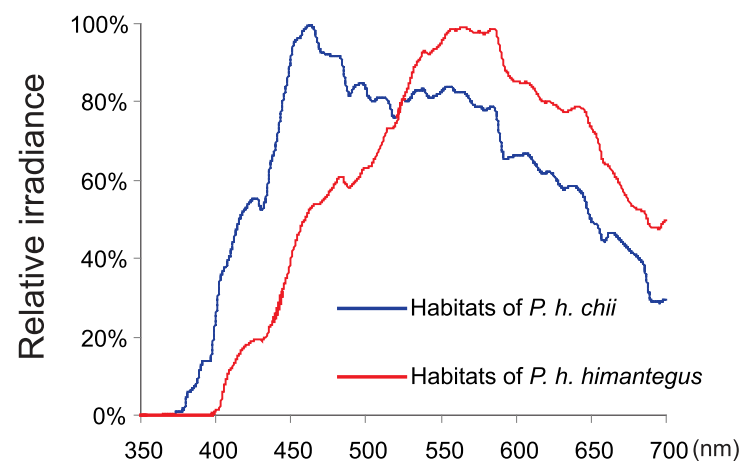

Fig. 4 Light spectra of the sampled habitats of studied species. a Upward light in air; b underwater upward light; c underwater sideward light. Light spectra shown are the geometric means of the measurements at the respective collection sites. Red: habitats of $P$. h. himantegus; Blue: habitats of P. h. chii. The original data are provided in Additional file 1

chii usually have a lower density of planktonic algae and clear/running water. Consequently, it has been suggested that $P . h$. himantegus dwells in locations where longer 
wavelength light predominates to a greater extent than that in the habitats of $P$. h. chii (Fig. 4).

The visual system is responsible not only for recognizing color signals but also for foraging for food or detecting predators. The light environment is a factor known to drive both the reception and production of visual signals of fishes (Hornsby et al. 2013; Hurtado-Gonzales et al. 2014; Shin and Choi 2014; Terai et al. 2006; Tezuka et al. 2014). Indeed, the present study showed that the spectral sensitivities of $P . h$. himantegus and $P$. h. chii are distinct: $P$. $h$. himantegus is more sensitive than $P$. $h$. chii to longer wavelength light, while it is less sensitive than $P$. h. chii at shorter wavelengths. As such, the spectral sensitivities of these subspecies are suitable for their respective ambient light conditions. Furthermore, the diverse nuptial colorations of these two bitterling subspecies may also result from the variation in the photic environments and/or the distinction of sensory properties.

Fishes commonly use UV signals in communication (Losey et al. 1999; Witzany 2014). In this study, ERG data demonstrated that both subspecies can perceive UV light, i.e., $370 \mathrm{~nm}$, and $P$. $h$. chii was more sensitive to UV light than $P$. h. himantegus, which is consistent with the light spectra of their respective habitats. However, since the body UV reflection patterns cannot be quantitatively compared between species, it is not possible to conclude whether the differences in UV sensitivity between the species are related to their body UV reflection patterns. However, the UV reflection patterns of the bitterlings were sexually dimorphic, suggesting that the UV pattern may be a secondary sexual characteristic in these fishes. Furthermore, the nuptial coloration of the males is a crucial signal for the mate choice of females, and the UV cue has been demonstrated to be a factor for nuptial coloration in many fishes (Garcia and Perera 2002; Kodric-Brown and Johnson 2002; Palmer and Hankison 2014; Rick et al. 2006; Smith et al. 2002). Our results imply that the UV reflection pattern of bitterlings may be an important characteristic for consideration in future taxonomic or ecological studies.

The diversification of $P$. nyererei and $P$. pundamilia cichlids is considered to be a good example of speciation caused by sensory drives (Miyagi and Terai 2013). A hypothesis posits that closely related and morphologically similar species should differ in mating signals, which is mainly engendered by three processes: habitat transmission, perceptual tuning, and signal matching. Habitat transmission is important when the habitat physically degrades the intensity of the signal during transmission; therefore, it is advantageous for signals to have a long transmitting distance (Bradury and Vehrencamp 2011; Morrill et al. 2013). Perceptual tuning is the phenomenon whereby some individuals may be inherently more sensitive to certain stimuli, e.g., a specific wavelength of light or frequency of sound, than other organisms, which may be a consequence of adaptation to their habitat (Boughman 2002). Signal matching refers to intimate coupling between the evolution of sexual display in the signal sender and the development of sensory capabilities in the signal receiver (Fisher 1915; Kirkpatrick 1982). Usually, mating signals are compatible with the receiver's perception capabilities, because a more detectable mating signal can increase the reproductive opportunities of the sender and reduce the search cost of the receiver (partner) (Dawkins and Guilford 1996), thereby improving reproductive success. Sensory drive speciation suggests that the gene flow between two sibling species is constrained during contact (Boughman 2002). Habitat transmission, perceptual tuning, and signal matching are all apparent in the two closely related Paratanakia subspecies examined in this study. Moreover, earlier genetic studies suggested that there is no gene flow between $P . h$. himantegus and P. h. chii (Chang et al. 2014; Chang et al. 2009b), and therefore, it is possible that speciation by sensory drive promotes differentiation of these two bitterlings.

Matsumoto et al. (2014) suggested that speciation by sensory drive most likely occurs when the sensory trait is determined by a small number of loci. Indeed, the visual spectral sensitivity is related to the opsin genes, e.g., long-wavelength-sensitive opsin gene $(l w s)$ in cichlids, zebrafish (Danio rerio), and three-spined stickleback (Seehausen et al. 2008; Shao et al. 2014), or shortwavelength-sensitive opsin gene $2 \mathrm{a}$ (sws $2 a$ ) in cichlids (Seehausen et al. 2008). Moreover, body coloration is also likely to be determined by a limited number of genes. For example, the male body coloration of East African cichlid, i.e., Pseudotropheus saulosi, may be controlled by only five genes (Gunter et al. 2011). Allopatric speciation (Bohlen et al. 2006) and switches in mussel host preference (Kitamura et al. 2012) have been suggested to be the main factors of bitterling diversification. Future studies of the genes that affect spectral sensitivity and nuptial coloration of these two Paratanakia bitterlings are needed to clarify the interactions between natural selection and sexual selection (Maan and Seehausen 2011). Such studies promise to clarify whether speciation by sensory drive promoted the speciation of these two Paratanakia bitterling subspecies.

\section{Conclusions}

We report that two morphologically similar and phylogenetically close bitterlings, $P . h$. himantegus and $P . h$. chii, have different nuptial colorations and spectral sensitivities and reside in habitats with different environmental photic conditions; these findings support the hypothesis that differences in nuptial coloration may be a consequence of variations in photic properties and spectral sensitivities and imply that speciation could be driven by the sensory system and related environmental 
conditions (Endler and McLella 1988), thereby promoting bitterling diversity. The spectral sensitivity and body UV reflection pattern data also support the hypothesis that the UV cue is a major component of the visual signals of bitterlings. While the UV cue may not be utilized in species recognition, it may assist bitterlings in gender identification.

\section{Additional file}

Additional file 1: The original data of relative ambient light spectra gathered from each of two habitats of Paratanakia himantegus himantegus and Paratanakia himantegus chii. In each sampling location, the relative spectral irradiance was smoothed by a factor of 15 using a simple moving average (McLean et al. 2007), and then normalized to a $0-100 \%$ scale, where $100 \%$ indicated the maximum intensity spectrum.

\section{Competing interests}

The authors declare that they have no competing interests.

\section{Authors' contributions}

CHC and YTS carried out the ERG measurements and UV reflection photography experiments, and wrote the first draft of the manuscript. KA designed and wrote the codes for the ERG recording and data analysis systems. WCF assisted in ERG recordings. YSL made comments on the manuscript. HYY provided logistical and financial support during the study, and revised the manuscript. All authors read and approved the final manuscript.

\section{Acknowledgements}

This study was supported by intramural research grants from Academia Sinica to HYY. During the course of manuscript preparation, $\mathrm{CHC}$ was supported by an overseas study fellowship from the Ministry of Science \& Technology, Taiwan (103-2917-I-009-003). YTS was supported by a postdoctoral fellowship from Academia Sinica. Dr. Duncan Wright performed English text editing.

\section{Author details}

'Department of Biological Science and Technology, National Chiao Tung University, Hsinchu, Taiwan. ${ }^{2}$ Department of Biology, St. Louis University, St. Louis, MO, USA. ${ }^{3}$ Sensory Physiology Laboratory, Marine Research Station, Academia Sinica, I-Lan, Taiwan. ${ }^{4}$ Present Address: Institute of Marine Biology, National Taiwan Ocean University, Keelung, Taiwan. ${ }^{5}$ Faculty of Fisheries, Kagoshima University, Kagoshima, Japan. ${ }^{6}$ Institute of Bioinformatics and Systems Biology, National Chiao Tung University, Hsinchu, Taiwan. ${ }^{7}$ Hanse-Wissenschaftskolleg Institute of Advanced Study, Delmenhorst, Germany.

Received: 15 January 2015 Accepted: 6 May 2015

Published online: 20 May 2015

\section{References}

Bohlen J, Šlechtová V, Bogutskaya N, Freyhof J (2006) Across Siberia and over Europe: phylogenetic relationships of the freshwater fish genus Rhodeus in Europe and the phylogenetic position of $R$. sericeus from the River Amur. Mol Phylogenet Evol 40:856-865

Boughman JW (2002) How sensory drive can promote speciation. Trends Ecol Evol 17:571-577

Bowling LC, Steane MS, Tyler PA (1986) The spectral distribution and attenuation of underwater irradiance in tasmanian inland waters. Freshw Biol 16:313-335

Bradury JW, Vehrencamp SL (2011) Principles of animal communication. Sinauer Associates, Inc., Sunderland, Massachusetts

Casalini M, Agbali M, Reichard M, Konečná M, Bryjová A, Smith C (2009) Male dominance, female mate choice, and intersexual conflict in the rose bitterling (Rhodeus ocellatus). Evolution 63:366-376
Chang C-H, Chiao C-C, Yan HY (2009a) Ontogenetic changes in color vision in the milkfish (Chanos chanos forsskål, 1775). Zool Sci 26:349-355

Chang C-H, Lin W-W, Shao Y-T, Arai R, Ishinabe T, Ueda T, Matsuda M, Kubota H, Wang FY, Jang-Liaw NH, Kao HW (2009b) Molecular phylogeny and genetic differentiation of the Tanakia himantegus complex (Teleostei: Cyprinidae) in Taiwan and China. Zool Stud 48:839-850

Chang C-H, Li F, Shao K-T, Lin Y-S, Morosawa T, Kim S, Koo H, Kim W, Lee JS, He S, Smith C, Reichard M, Miya M, Sado T, Uehara K, Lavoué S, Chen WJ, Mayden RL (2014) Phylogenetic relationships of Acheilognathidae (Cypriniformes: Cyprinoidea) as revealed from evidence of both nuclear and mitochondrial gene sequence variation: evidence for necessary taxonomic revision in the family and the identification of cryptic species. Mol Phylogenet Evol 81:182-194

Chen I-S, Chang Y-C (2005) A photographic guide to the inland-water fishes of Taiwan. The SueiChan Press, Keelung

Chen I-S, Tzeng C-S, Shao K-T (2012) Red data book of freshwater fishes in Taiwan. Forestry Bureau, Council of Agriculture, Executive Yuan, Taipei, Taiwan

Cheng CL, Flamarique IN (2004) Opsin expression: new mechanism for modulating colour vision. Nature 428:279

Chunco AJ, McKinnon JS, Servedio MR (2007) Microhabitat variation and sexual selection can maintain male colour polymorphisms. Evolution 61:2504-2515

Dalton BE, Cronin TW, Marshall NJ, Carleton KL (2010) The fish eye view: are cichlids conspicuous? J Exp Biol 213:2243-2255

Dawkins MS, Guilford T (1996) Sensory bias and the adaptiveness of female choice. Am Nat 148:937-942

Endler JA (1980) Natural selection on color patterns in Poecilia reticulata. Evolution 34:76-91

Endler JA (1990) On the measurement and classification of color in studies of animal color patterns. Biol J Linn Soc 41:315-352

Endler JA (1992) Signals, signal conditions, and the direction of evolution. Am Nat 139: Supplement:125-153

Endler JA, McLella T (1988) The processes of evolution: toward a newer synthesis. Annu Rev Ecol Syst 19:395-421

Fisher RA (1915) The evolution of sexual preference. Eugen Rev 7:184-192

Flamarique IN (2013) Opsin switch reveals function of the ultraviolet cone in fish foraging. Proc R Soc B Biol Sci 280:20122490

Flamarique IN, Cheng CL, Bergstrom C, Reimchen TE (2013) Pronounced heritable variation and limited phenotypic plasticity in visual pigments and opsin expression of threespine stickleback photoreceptors. J Exp Biol 216:656-667

Fuller RC, Carleton KL, Fadool JM, Spady TC, Travis J (2005) Genetic and environmental variation in the visual properties of bluefin killifish, Lucania goodei. J Evol Biol 18:516-523

Garcia CM, Perera T (2002) Ultraviolet-based female preferences in a viviparous fish. Behav Ecol Sociobiol 52:1-6

Gray SM, Dill LM, Tantu FY, Loew ER, Herder F, McKinnon JS (2008) Environment-contingent sexual selection in a colour polymorphic fish. Proc R Soc B Biol Sci 275:1785-1791

Gunter HM, Clabaut C, Salzburger W, Meyer A (2011) Identification and characterization of gene expression involved in the coloration of cichlid fish using microarray and QRT-PCR approaches. J Mol Evol 72:127-137

Hawryshyn CW (1992) Polarization vision in fish. Am Sci 80:164-175

Hoffmann M, Tripathi N, Henz SR, Lindholm AK, Weigel D, Breden F, Dreyer C (2007) Opsin gene duplication and diversification in the guppy, a model for sexual selection. Proc R Soc B Biol Sci 274:33-42

Hornsby MAW, Sabbah S, Robertson RM, Hawryshyn CW (2013) Modulation of environmental light alters reception and production of visual signals in Nile tilapia. J Exp Biol 216:3110-3122

Hurtado-Gonzales JL, Loew ER, Uy JAC (2014) Variation in the visual habitat may mediate the maintenance of color polymorphism in a poeciliid fish. PLos One 9, e101497

Jerlov NG (1976) Marine optics. Elsevier Amsterdam, Kingdom of the Netherlands Johnson AM, Stanis S, Fuller RC (2013) Diurnal lighting patterns and habitat alter opsin expression and colour preferences in a killifish. Proc R Soc B Biol Sci 280:20130796

Kasagi S, Mizusawa K, Murakami N, Andoh T, Furufuji S, Kawamura S, Takahashi A (2015) Molecular and functional characterization of opsins in barfin flounder (Verasper mosen). Gene 556:182-191

Kirkpatrick M (1982) Sexual selection and the evolution of female choice. Evolution 36:1-12 
Kitamura J, Nagata N, Nakajima J, Sota T (2012) Divergence of ovipositor length and egg shape in a brood parasitic bitterling fish through the use of different mussel hosts. J Evol Biol 25:566-573

Kodric-Brown A, Johnson SC (2002) Ultraviolet reflectance patterns of male guppies enhance their attractiveness to females. Anim Behav 63:391-396

Kondrashev SL, Miyazaki T, Lamash NE, Tsuchiya T (2013) Three cone opsin genes determine the properties of the visual spectra in the Japanese anchovy, Engraulis japonicus (Engraulidae, Teleostei). J Exp Biol 216:1041-1052

Kottelat M, Freyhof J (2007) Handbook of European freshwater fishes. Kottelat Freyhof Cornol, Switzerland and Berlin, Germany

Lisney TJ, Studd E, Hawryshyn CW (2010) Electrophysiological assessment of spectral sensitivity in adult nile tilapia Oreochromis niloticus: evidence for violet sensitivity. J Exp Biol 213:1453-1463

>Litjens RAJ, Quickenden TI, Freeman CG (1999) Visible and near-ultraviolet absorption spectrum of liquid water. Appl Opt 38:1216-1223

Loew ER, McFarland WN, Margulies D (2002) Developmental changes in the visual pigments of the yellowfin tuna, Thunnus albacares. Mar Freshw Behav Physiol 35:235-246

Losey GS, Cronin TW, Goldsmith TH, Hyde D, Marshall NJ, McFarland WN (1999) The UV visual world of fishes: a review. J Fish Biol 54:921-943

Lythgoe JN (1984) Visual pigments and environmental light. Vis Res 24:1539-1550

Maan ME, Seehausen O (2011) Ecology, sexual selection and speciation. Ecol Lett 14:591-602

Maan ME, Seehausen O, Söderberg L, Johnson L, Ripmeester EAP, Mrosso HDJ, Taylor MI, van Dooren TJ, van Alphen JJ (2004) Intraspecific sexual selection on a speciation trait, male coloration, in the Lake Victoria cichlid Pundamilia nyererei. Proc R Soc Lond Ser B 271:2445-2452

Maan ME, Hofker KD, van Alphen JJM, Seehausen O (2006) Sensory drive in cichlid speciation. Am Nat 167:947-954

Matsumoto T, Terai Y, Okada N, Tachida H (2014) Sensory drive speciation and patterns of variation at selectively neutral genes. Evol Ecol 28:591-609

McDonald CG, Hawryshyn CW (1995) Intraspecific variation of spectral sensitivity in threespine stickleback (Gasterosteus aculeatus) from different photic regimes. J Comp Physiol A 176:255-260

McLean IS, Prato L, McGovern MR, Burgasser AJ, Kirkpatrick JD, Rice EL, Kim SS (2007) The nirspec brown dwarf spectroscopic survey. II. High-resolution $j$-band spectra of $\mathrm{m}, \mathrm{l}$, and $\mathrm{t}$ dwarfs. Astrophys J 658:1217-1235

Miyagi R, Terai Y (2013) The diversity of male nuptial coloration leads to species diversity in Lake Victoria cichlids. Genes Genet Syst 88:145-153

Miyagi R, Terai Y, Aibara M, Sugawara T, Imai H, Tachida H, Mzighani SI, Okitsu T, Wada A, Okada N (2012) Correlation between nuptial colors and visual sensitivities tuned by opsins leads to species richness in sympatric Lake Victoria cichlid fishes. Mol Biol Evol 29:3281-3296

Morita Y, Meyer-Rochow VB, Uchidaa K (1997) Absolute and spectral sensitivities in dark- and light-adapted pagothenia borchgrevinki, an antarctic nototheniid fish. Physiol Behav 61:159-163

Morrill RJ, Thomas AW, Schiel N, Souto A, Miller CT (2013) The effect of habitat acoustics on common marmoset vocal signal transmission. Am J Primatol 75:904-916

Morrongiello JR, Bond NR, Crook DA, Wong BBM (2010) Nuptial coloration varies with ambient light environment in a freshwater fish. J Evol Biol 23:2718-2725

Palmer MS, SJ Hankison (2014) Use of ultraviolet cues in female mate preference in the sailfin molly, Poecilia latipinna. Acta Ethol (early online)

Pitcher TJ (1986) The behaviour of teleost fishes. Springer US, New York, USA

Reichard M, Smith C, Bryja J (2008) Seasonal change in the opportunity for sexual selection. Mol Ecol 17:642-651

Rick IP, Modarressie R, Bakker TCM (2006) UV wavelengths affect female mate choice in three-spined sticklebacks. Anim Behav 71:307-313

Seehausen O, Bouton N (1997) Microdistribution and fluctuations in niche overlap in a rocky shore cichlid community in Lake Victoria. Ecol Freshw Fish 6:161-173

Seehausen O, Terai Y, Magalhaes I, Carleton KL, Mrosso HDJ, Miyagi R, van der Sluijs I, Schneider MV, Maan ME, Tachida H, Imai H, Okada N (2008) Speciation through sensory drive in cichlid fish. Nature 455:620-627

Seeliger MW, Rilk A, Neuhauss SCF (2002) Ganzfeld erg in zebrafish larvae. Doc Ophthalmol 104:57-68

Selz OM, Pierotti MER, Maan ME, Schmid C, Seehausen O (2014) Female preference for male color is necessary and sufficient for assortative mating in 2 cichlid sister species. Behav Ecol 25:612-626
Shao YT, Wang F-Y, Fu W-C, Yan HY, Anraku K, Chen I-S, Borg B (2014) Androgens increase IWs opsin expression and red sensitivity in male three-spined sticklebacks. PLos One 9, e100330

Shin HS, Choi CY (2014) The stimulatory effect of led light spectra on genes related to photoreceptors and skin pigmentation in goldfish (Carassius auratus). Fish Physiol Biochem 40:1229-1238

Smith EJ, Partridge JC, Parsons KN, White EM, Cuthill IC, Bennett ATD, Church SC (2002) Ultraviolet vision and mate choice in the guppy (Poecilia reticulata). Behav Ecol 13:11-19

Smith C, Phillips A, Polačik M, Reichard M (2014) Male coloration signals direct benefits in the European bitterling (Rhodeus amarus). Environ Biol Fish 97:335-341

Sugawara T, Terai Y, Imai H, Turner GF, Koblmüller S, Sturmbauer C, Shichida Y, Okada N (2005) Parallelism of amino acid changes at the RH1 affecting spectral sensitivity among deep-water cichlids from Lakes Tanganyika and Malawi. Proc Natl Acad Sci U S A 102:5448-5453

Terai Y, Seehausen O, Sasaki T, Takahashi K, Mizoiri S, Sugawara T, Sato T, Watanabe M, Konijnendijk N, Mrosso HDJ, Tachida H, Imai H, Shichida Y, Okada N (2006) Divergent selection on opsins drives incipient speciation in Lake Victoria cichlids. PLos Biol 4, e433

Tezuka A, Kasagi S, Oosterhout CV, McMullan M, Iwasaki WM, Kasai D, Yamamichi M, Innan H, Kawamura S, Kawata M (2014) Divergent selection for opsin gene variation in guppy (Poecilia reticulata) populations of Trinidad and Tobago. Heredity 113:381-389

Valen R, Edvardsen RB, Søviknes AM, Drivenes $\varnothing$, Helvik JV (2013) Molecular evidence that only two opsin subfamilies, the blue light- (SWS2) and green light-sensitive $(\mathrm{RH} 2)$, drive color vision in Atlantic cod (Gadus morhua). PLos One 9, e115436

Wang FY, Yan HY, Chen JS-C, Wang TY, Wang D (2009) Adaptation of visual spectra and opsin genes in seabreams. Vis Res 49:1860-1868

Wang FY, Tang MY, Yan HY (2011) A comparative study on the visual adaptations of four species of moray eel. Vis Res 51:1099-1108

Witzany G (2014) Biocommunication of animals. Springer, Dordrecht, Netherlands

\section{Submit your manuscript to a SpringerOpen ${ }^{\circ}$ journal and benefit from:}

- Convenient online submission

- Rigorous peer review

- Immediate publication on acceptance

- Open access: articles freely available online

- High visibility within the field

- Retaining the copyright to your article

Submit your next manuscript at springeropen.com 